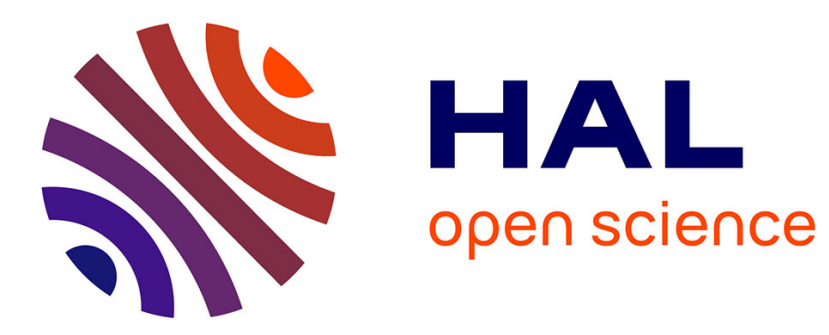

\title{
A Brief Guide for the Chemistry Entrepreneur
}

Alexander Sachse, Javier Garcia Martinez

\section{To cite this version:}

Alexander Sachse, Javier Garcia Martinez. A Brief Guide for the Chemistry Entrepreneur. A Brief Guide for the Chemistry Entrepreneur, pp.91-107, 2016, 10.1021/bk-2016-1219.ch011 . hal-03033508

\section{HAL Id: hal-03033508 https://hal.science/hal-03033508}

Submitted on 1 Dec 2020

HAL is a multi-disciplinary open access archive for the deposit and dissemination of scientific research documents, whether they are published or not. The documents may come from teaching and research institutions in France or abroad, or from public or private research centers.
L'archive ouverte pluridisciplinaire HAL, est destinée au dépôt et à la diffusion de documents scientifiques de niveau recherche, publiés ou non, émanant des établissements d'enseignement et de recherche français ou étrangers, des laboratoires publics ou privés. 


\title{
A Brief Guide for the Chemistry Entrepreneur
}

\author{
Alexander Sachse, ${ }^{a}$ Javier Garcia Martinez ${ }^{a, b}$ \\ ${ }^{a}$ Department of Inorganic Chemistry, Universidad de Alicante, \\ Alicante, Spain \\ ${ }^{b}$ Rive Technology Inc., 1 Deer Park Drive, Suite A, \\ Monmouth Junction, NJ 08852, NJ, USA \\ Email: j.garcia@ua.es
}

\begin{abstract}
"When starting a company, you can listen to everyone's advice, but oftentimes, it does not matter. If you do not live it, you will not learn it". This is generally the answer that we get when asking a chemistry entrepreneur the question: what does it take to bring an invention to the market? Yet, there exist many valuable tools designed to support successful business creation and to identify its key steps.

The first and one of the most important things we need to bear in mind when aiming at creating a company is the capacity of self-assessment, i.e. the ability to know and to evaluate oneself. It is indeed crucial to be aware of one's skills, strengths and expertise as well as to own a precise idea of our envisaged business and its implementation. Whilst, appropriate work experience in the area we want our industry to produce in is fundamental, we should not be afraid to venture out into the unknown. Essential business skills can be learned with the appropriate diligence. The most important concern to become a chemistry entrepreneur is that we should know what we want to do with the rest of our lives.

It is crucial to have a good business idea, which should identify a key niche and satisfy a need by its realization. There
\end{abstract}


should exist no ambiguity whether our idea presents what it requires to becoming a real market opportunity. We should hence be in measure to define a given target market. Equally, it is fundamental to identify potential competitors and to assure the intellectual property that covers our business idea.

Once these initial issues are clarified the establishment of a versatile business plan is of upmost importance. A business plan is an extremely useful tool as it permits to bundle our ideas whilst generating an efficient business strategy leading to success. The business plan allows to determine the course of action, assessment of responsibilities and formulation of the company's milestones. This is a time consuming and exhausting process, yet crucial if we aim at the success of the realization of our idea.

Finally and most importantly, we need to determine the financial structure of our company, as most chemical entrepreneurs cannot realize their invention without an efficient funding strategy.

In this article we will fathom the most essential concepts for realizing an invention to become a business idea from its beginnings to setting-up the company and to highlight its substantial key requirements. Further we will depict Rive technology as case study to successful business creation.

\section{The birth of the business Idea: The Eureka Moment}

One of the best things of being a chemist is the feeling of joy - this is the sensation we have when we achieve something new for the first time; the wellknown Eureka effect. Yet, an even better and by far more fascinating adventure is to bring the invention to the market. Along this intriguing journey many new concepts have to be learned and applied, such as cost, ownership of intellectual property and prior art, government regulations; concepts to which chemists are oftentimes not very familiar with. Many constraints arise throughout this challenge and we need to be prepared in order to circumvent major inconveniences that could hinder and infringe commercial success of our invention.

\section{Key factors for a successful business idea}

If we have in mind of commercializing an invention we need to stop to think as a researcher. What we need to commercialize our invention is not a 
research proposal but a vision. It is worth emphasizing that proposing a single product is not enough for creating a company. This is a typical mistake for academic entrepreneurs. A vision can be represented by a concept such as a technology platform that permits us to realize various products allowing to resolve a need that market has yet not done. To have a vision furthermore supports us to be versatile and to adapt to rapid market changes. Competition is vigorous and it is not because we produce the best product that competitors will not put something on the market that works even better at a keener price. It is essential to sediment in our minds that it is the clients that determine our business strategy. A vision is hence crucial to have a greater picture beyond our product.

To have an idea is definitely the first step in any entrepreneurs' life. Yet, we should bear in mind that the business world is regardless of any beauty of a given invention. What really matters is if the idea has the potentiality to generate profit. The availability of a market opportunity is a key aspect that needs to be considered. Researchers frequently are troubled of not being sure whether a company can be created around a given product. To remedy this dilemma we merely need to be in the possibility of answering the question: how much of my product do I need to sell and to what cost in order to establish a strong company? The size and strength of the company we aim to create depends mainly on the prize we can sell our product and to how many purchasers there exist.

Having an idea and knowing the market are essential attributes that need to be assessed before of any realistic consideration of company realization. Yet, the process of building up the company is tricky as many unforeseeable trap doors exist. A typical mistake many academic entrepreneurs slip up with is to believe that they are self-sufficient. Yet, nobody is capable of knowing everything. It is thus important to recognize our limitations and to share duties by forming an efficient team. This can go as far as hiring a CEO who himself has nothing to do with the conception of our initial idea, but who becomes part of our vision.

An additional key factor is determinant for the development of our company which is money. No business can be created without money. We need money in order to generate profit and we should be aware how funding works on all levels.

\section{Reasons why many companies fail}

The above-mentioned key factors are essential for the successful growth and development of our company. A majority of industries fail in their infancy mainly due to the fact that the above mentioned key features are not fully respected. Many researchers have an idealized idea of the commercialization of their technology or product and are not aware of the wind that blows out in the business world. 
Under no circumstances should we aspire to creating a company out of love for the technology or for the mere desire of advancing technology. Launching a company is not a research proposal. An important amount of time academics spend with, is fundraising, yet by no means should we try to fund a research project through investors. We must be aware that investors need to be paid back several times the amount of money they have invested, hence we should be convinced that our product has the power to generate profit.

Another typical pitfall is the idea that launching a company could be beneficial to improve our CV. This is not the case. Starting a company represents years of academic sacrifice in which we will hardly publish scientific papers. If our goal is to boost our CV then we should do this by writing high quality papers and books.

Becoming an independent researcher becomes more and more difficult nowadays and many especially young scientists fell frustrated of being unable of attaining a fixed position within academia. In this respect, creating a company represents a way out of this quandary and permits furthermore to be one's own boss. Yet, we should be aware that the conception of the term boss does no longer apply to modern companies. Being the founder of a company rarely feels like being its chief. It's the team that shapes the business.

\section{How to assess if our business idea is promising for setting up a company?}

Researchers oftentimes have the doubt of not knowing whether an idea has what it takes to be converted into a successful business. The first question we need to be able to answer is: is there a demand for our product? In other words, are customers willing to pay for our product? To answer this question we need to identify a target market, to understand if our product is unique and if our product we aim at producing is free of any legal implications. If we are not completely sure of being able to find the right answer to the question we need to realize that what we are offering is not strong enough and the best thing we can do is to work on our idea or to develop a new one.

\section{Business plan: on the way to creating our business}

The concept of the business plan has evolved essentially during the past decades. Previously a business plan was meant to be highly developed and was represented by a lengthy document to which the company had to adhere rigorously and that would not be altered after its approval. This rigorous

conception of the plan did not enable any possibility to flexibility. In the fast 
moving times we live in this conception is no longer valid as it represents a major drawback.

Nowadays, the notion of the business plan has radically changed, and provides versatility to our idea to adapt to the market. A successful business plan is meant to clarify our idea, define the long term objectives and provide a blueprint for funding our business. The business plan must include a valid business concept, disclose markets and competitors, define sales and marketing strategy, draft the management team and the financial requirements and finally assess possible risk our company runs to fail.

Setting up the business plan generally follows the principles of The Chemistry Lean LaunchPad (4). This Pad consists out of nine distinct elements that determine the development of the business plan and concretely consist to: (i) identify the customer segment (i.e. who are our clients); (ii) define the value proposition (i.e. our vision); (iii) determine the channels through which the customer segments should be reached; (iv) determine the type of the expected relationship with each of our customer segments; (v) determine the revenue stream (i.e. to define the value for which our customers are willing to pay); (vi) determine our key resources that our value proposition requires (i.e. workforce, technology, Intellectual Property rights); (vii) determine our key activity that our value proposition requires to be successful; (viii) identify our key partners (i.e. who are our business associates that are required to commercialize our product); (ix) determine the cost structure (i.e. establish which are the most important costs inherent to our business model).

The Chemistry Lean LaunchPad can be well conveyed through the concept of "pivoting." This merely implies to create hypothesis, which need to be verified with our clients. It is essential to realize customer needs and to validate the invention with our customers. By doing so, we are enabled to going back to the original idea and to refine it as many times as possible potential customers can be established before creating the company. This is a fundamental key step as it is the clients who decide on the success of our business.

\section{Communication: An indispensable key skill of the chemistry entrepreneur}

Communication is a key skill that allows us to approach customers and permits for successful negotiations. Communication further enables us to inquire about market needs and to identify those how are willing to purchase our product. Thus, continuous communication with customers to refine our value proposition is of upmost importance.

A great variety of tutorials exist that explain the principles of efficient communication. We here merely aim at emphasizing some of the most important 
aspects of business-minded communication. It is always smart to keep in mind to the nature of the audience we are referring. Therefore, we need to determine and to adapt our speech. It is not equal exposing our idea to a research colleague or to an investor. The vulgarization of our vision is of extreme importance, i.e. to put it in very simple terms, yet to be able to distill the essence of the innovative aspects our product we aim at commercializing presents. We should bear in mind that potential customers and investors will try to destabilize us on purpose to grasp the strength of our arguments as well as our determination to realize our company. Therefore, eye contact and body language are of upmost importance as we do not merely communicate through oral language. A reposed yet dynamic attitude is important to make an impact. Finally we should be prepared and we should know exactly at all times about what we are talking. The loss of confidence represents a major risk when planning at creating a business.

\section{Identifying the market: who are our customers and how to approach them?}

A chemical company can produce a great variety of different products, such as services, technology or devices. Despite the nature of our product, we need to identify customers and potential customers that are willing to pay for it.

The best way of identifying potential customers is to focus to a specific customer group, which can generally be easily disclosed by market survey. Once we establish a group of potential customers we should find out their opinion on the product we are trying to offer. Key questions here are: is our product a valid alternative the potential consumer would buy? And if yes, under which conditions?

It is further important to realize that generally the first contact with a potential customer will not allow to make a deal. The firs contact will hardly lead to an appointment for presenting our product and to make a sales presentation. We need to be insistent, yet without being too obtrusive. We will barely be invited to present our product if we show no credibility right from the first contact.

When invited by a potential customer, we should prepare the best possible presentation and arguments why our product should be purchased. We should exactly know the customers' business and its reality. A good tactic can be to ask customers in which way we can help to maintain and grow their business by our product or technology.

A good strategy to understand customers' decisions is to ask for feedback. This allows us to learn and improve the way we approach and negotiate with consumers. This approach further helps us to realize limitations our product may feature. 


\section{Who are our competitors?}

Whether our company will be successful depends in many cases on the competition there is out on the market. If our product proposes a unique solution, than our company will be the sole that produces it. Yet, this is an idealization too many researchers do. Generally alternatives to our product exist and we have to distinguish our product importantly to the one of competitors. An essential step before any business creation is to disclose any competitors and potential competitors.

There are two ways that allow for the determination of competitors. The first and most obvious way is to search for companies producing similar products or those that have similar know-how. The second strategy is to disguise competitors by their customers. This leads to a wide view of existing competitors and to realize the threat they present for our company. Under no circumstance should we underestimate the number of potential rivals. For getting a clear picture of our competitors we should exactly know which technology or product they are selling.

If our idea is to bring a new catalyst for a given reaction on the market than we should understand which commercial alternatives to our catalyst exist. Competitors may produce a similar catalyst but to a different scope, how can we assure that they will not sell their catalyst to the same scope as ours once we are on the market? Hence it is of upmost importance to grasp what our competitors are up to in order to be at the forefront. The strategy to that is that we should try as best as possible how our closest rivals will react to the creation of a new competitor (i.e. our company) and how we can foresee the market strategy they will apply.

\section{Hinder others to realize our invention: Protection through Intellectual Property}

We can set up a business producing the best alternative available on the market. Yet we must prevent by all means that other enterprises (i.e. competitors) copy our product. Therefore Intellectual Property rights exist and it is important that we know how to protect our invention through a maximum of claims.

We can demand Intellectual Property rights for any invention that presents well defined characteristics fulfilling the patentability criteria's. Our invention 
must present novelty and needs to rely on an inventive step (i.e. beyond the state-of-the-art). An invention further needs to present industrial applicability. The Intellectual Property right is granted as a patent. A patent provides its applicant with exclusive rights to prevent others from possessing, using, selling, manufacturing and importing the patent invention or offering it to do any of these means within a defined geographical area. Patents may be granted for any invention concerned with the functional and technical aspects of products and processes, i.e. product patents and process patents. Yet, it is important to be conscious that we are not allowed to apply a process-patent to a given product if the product is covered by Intellectual Property by a third party.

The geographical extension of the Intellectual Property extends to the national borders of the countries in which protection has been claimed. Intellectual Property for a given invention can be sought at national patent offices, the European Patent Office (EPO), or by solicitation an international patent through a so called PCT (patent cooperation treaty) application.

It is furthermore important to be aware that patents have an important cost that varies in function of the geographical area for which protection is sought and duration of the patent. Indeed patent maintenance costs increase exponentially throughout the life of a granted patent, within a limit of 20 years. Once this time period elapsed anyone can use our technology and produce liberally our product to offer it on the market. It is important to be ahead of other. Once our Intellectual Property rights expire we need to adapt our product in order to stay at the forefront. This highlights the importance of creating the company around a vision instead as on a single product.

\section{Life cycle of the entrepreneurship project}

Most companies develop essentially throughout time. Generally we talk about the company's life cycle. Some companies have developed efficient strategies and perdure throughout decades and even centuries. Figure 1 represents a typical life cycle of a chemical company. In the beginning of the creation important cost arise related to production and development of the product. Yet revenues take some time to ingress. This situation generates a negative cash flow. Hence, this stage is frequently referred as the Valley of Death. It is the depth of this valley that decides on the survival of our company. Indeed many companies do not manage to overcome this crucial stage.

Eventually, sales increase by finding new customers willing to pay for our product. During this stage our company grows essentially, yet cash flow is still negative and it is important to develop an efficient growth strategy. Once sales exceed costs a positive cash flow is registered, which means the company is generating a surplus. This stage is designed as the maturity phase of our company. Yet, our industry is not protected from decline, which is the case 
when income drops to or below the level of costs. This can for example be the case when a patent expires and a competitor brings the same, a similar or a better product on the market and eventually to a lower price.

Especially in the chemical sector the costs related to development and production correspond to an enormous cost effort, which means that the duration in which we require funding is particularly extended. Funding is essential throughout the entire time period the company registers a negative cash flow. It is important to be conscious that the Valley of Death is especially deep in the chemistry sector. Efficient fundraising is required to survive this stage and must then adapt to the growth phase of the company.

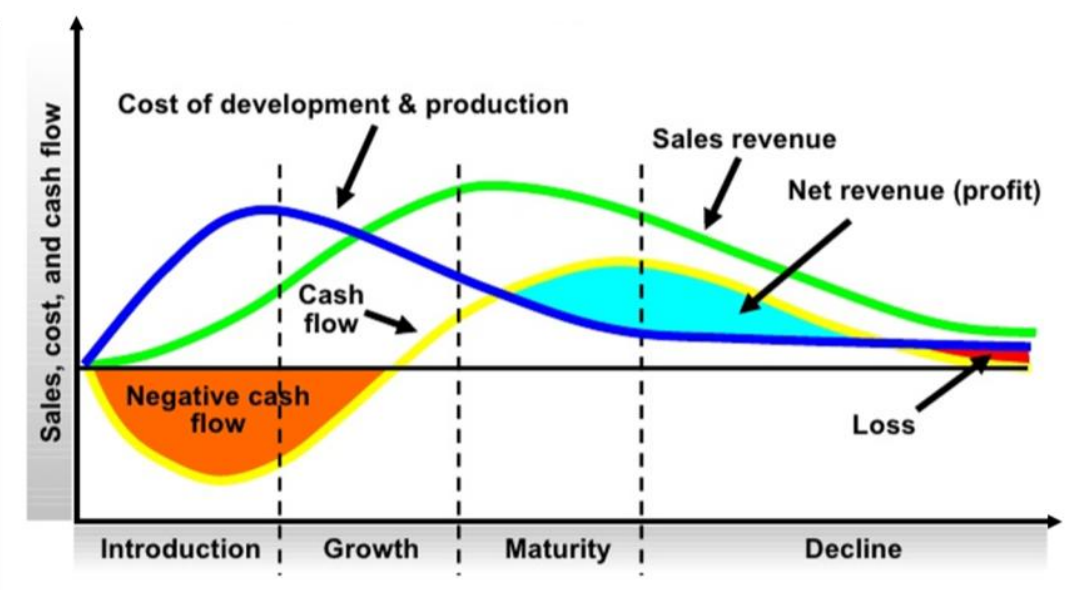

Figure 1. Example of the life cycle of a chemical company.

\section{Fundraising}

No company can be created without the appropriate financial structure. During the introduction and growth phase of our company we need to survive without registering any positive cash flow. This can only be achieved through efficient fundraising, as represented in figure 2. The nature of the financing institution depends particularly on the company's situation and is strongly connected to the notion of risk. By achieving essential milestones the risk to fail decreases. A milestone is represented by a major achievement that can be registered. In the chemical sector the first milestone is oftentimes constituted by the granting of the first patent (an important prerequisite to protect our product or technology). Once the first milestone achieved we can start with searching for funds. Typically, in this first instance of business creation investment is assured by so called Business Angels (i.e. affluent individuals who provide capital for a 
business start-up, usually in exchange of convertible debit or ownership equity). This first financial injection needs to permit us to achieve a subsequent milestone which generally presents a portfolio of clients. At this stage our company overcomes the Valley of Death, which means that the risk of our company to fail has substantially diminished. At this point more important investment can be sought through so called Venture Capitalists, who permit our company to grow at a steady state up to the stage of industrial production. Venture Capitalists are usually formed by institutions that invest other people's money which they manage for them.

Once our company established itself as well-working profit producing industry our risk to fail is substantially low and further investment through e.g. Investment Banks can be sought which permits to establish a big and leading chemical company.

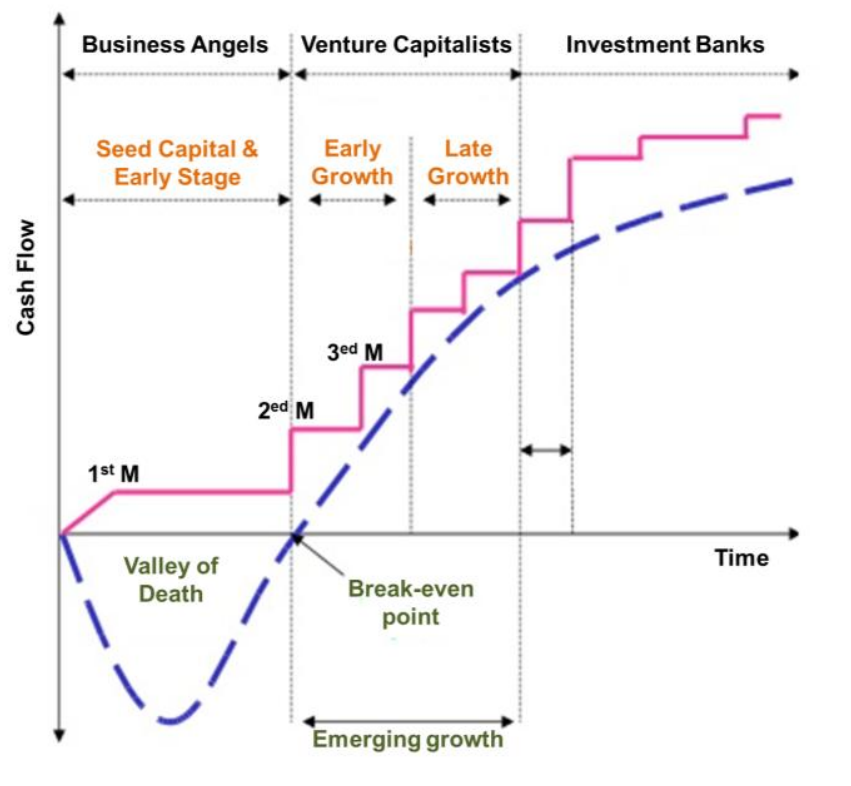

Figure 2. Financial life cycle of a chemical company.

\section{How to find funding?}

The precedent section highlighted the requirement for funding throughout an important time period our company gets started and grows. It is important to convince investors of your vision. This can only be done by presenting a clear, 
transparent and satisfying business strategy. We should be aware that potential investors have the choice between an important number of business plans, hence we should make sure that ours sticks out of the lot. Though the principal idea should be clear from the first glance, the plan must be sufficiently completed and throughout convincing. Therefore, we should present a strong management structure, ideally by proving previous experience. Furthermore, we should make sure that our idea is covered by Intellectual Property rights, as no investor will be willing to invest in a company which product can readily be copied by anyone.

When presenting our idea to a potential investor we should expose our full vision, as investors are oftentimes interested to a window of opportunities instead as in financing a one-product company. We should also highlight the market potential of our product, for this a strong and clear objective is essential. It is of upmost importance that the business plan reveals our background, our experience and our drive to launch the company.

Throughout the creation of our company we should be aware that nobody is willing to give us money without receiving a counterpart. Two basic types of financing exist independent of the financing source. These are equity financing and debt financing. Whilst in equity financing we receive capital in exchange of a part of the ownership of our company, in debt financing we need to pay back the loan we obtain. A chemical company is usually funded through equity financing.

This means that we will have to cease share of stocks of our company. A share is indeed defined as a unit of account for investment. In other words we as founder of our company have to realize that an essential part of the company does no longer belong to us but is disposed to the integrity of shareholders. Another possibility is that the investor becomes a partner of the company and will be concerned with its managing structure.

\section{Case Study: Rive Technology; an exemplary example of successful business creation}

Rive Technology was founded in 2006 and is headquartered in Boston with a research-and-development branch in Princeton, N.J. The MIT Executive Summary Report from February 2009 depicted Rive Technology as young and fast-growing company, funded by the MIT alumnus Dr. Javier Garcia Martinez. At that time, Rive Technology was still in its experimental stages, employing merely two people and working hard to determine whether the designed technology could be effectively translated into a business opportunity. Today, Rive Technology is a large company producing structured catalysts for separations processes, such as those used to refine petroleum, produce chemicals and biofuels, and purify air and water for increase process efficiency. 
Rive commercializes its technology through W.R. Grace. In mid-2010 Rive and Grace entered into a joint development and commercialization program to combine Rive's innovative technology with Grace's capabilities in catalyst formulation and manufacturing. The companies are jointly developing and marketing breakthrough fluid catalytic cracking (FCC) catalysts. Since 2013, the technology is commercialized (1).

Rive has raised more than $\$ 67$ million in venture capital. After successful scale-up and extensive pilot plant study, the prepared catalysts are being used in commercial refineries providing enhanced flexibility, better selectivity, and profitability that we are using to expand our technology to new processes.

\section{Molecular Highway Technology}

Technical context and understanding the problem

Most catalysts used in the refining industry are constructed out of zeolites. These are crystalline inorganic materials characterized by an open framework of atoms including silicon, aluminum and oxygen. When taken together, they form an open structure of micro-pores (with dimensions below $1 \mathrm{~nm}$ ). This structure makes zeolites very effective catalysts providing access to reactants, or feed molecules. In petroleum refining, long hydrocarbon chains, or feed molecules, enter the zeolite crystal through the micro-pores and are channeled to the active sites inside the zeolite crystal. Once inside the pores, the long hydrocarbon chains are converted, or "cracked", into small, more valuable product molecules, such as gasoline, diesel, or other products.

Yet, current zeolites suffer from a performance limitation due to the size of their micro-pores. As a result, longer hydrocarbons cannot fit through the small openings of the micro-pores and are blocked, preventing them from being cracked into more valuable products. Furthermore, the hydrocarbons that do make their way into the micro-pores are at risk of over-cracking, which can result in the production of undesirable byproducts, such as light gases. This limitation in diffusion decreases product yields, product efficiency, and ultimately, profits.

\section{Rive's product solution}

Understanding the problem with existing zeolite catalysts, Rive Technology offers a nano-engineered solution with its Molecular Highway Technology. When applied to the zeolite structure, Molecular Highway Technology creates larger mesopores $(2-50 \mathrm{~nm}$ in diameter), or "molecular highways", in the latticework of the zeolite. These molecular highways improve diffusion into and out of the structure, allowing feed molecules improved access to the zeolite structure, where they are converted. This allows for the longer 
hydrocarbons, which previously could not access the structure, to diffuse through the catalysts and be cracked into the desired products. Moreover, the molecular highways are large enough that the product molecules exit the structure rapidly before over-cracking can occur into undesirable byproducts.

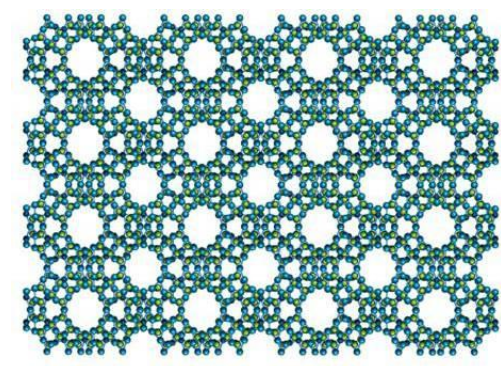

Conventional zeolite

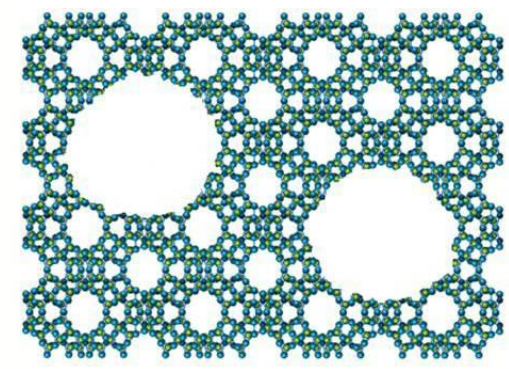

Zeolite with molecular highways

Figure 3. Rive's proposed product solution.

With the Molecular Highway Technology, it is possible to control and optimize the concentration and size of the mesopores across a wide range of zeolite structures for specific applications. This technology is applicable to many zeolite processes that are diffusion-controlled, which improves product yields, efficiency, and economic performance $(2,3)$.

\section{Company Evolution}

In the beginning, the company operated very cheaply, moving to Oklahoma to scale up the technology. Since then, however, Rive Technologies has raised a significant amount of money and is nearing closure on a fifth round of funding for a total of $\$ 100$ millions. This is a serious amount of money, but it comes with the territory. If you want to change how gasoline and diesel are made on a global scale, spending large amounts of money is inevitable.

In keeping with its large financial scale, the company has a range of very good investors, such as Blackstone, Mitsui Chemicals, and Saudi Aramco.

Since its modest beginning in Oklahoma, Rive has scaled up significantly and become an international company. Headquartered in Boston, MA, the company has its R\&D headquarters in Princeton, $\mathrm{NJ}$, and additional domestic offices in Denver, CO, and Houston, TX. Some of Rive's global partners are from Europe, the Middle East, and Asia, with a portion of production in China. As a result, issues revolving around logistics, intellectual property, and working well with international partners are of critical importance.

The global scale of Rive is a natural evolution of its industry. When attempting to change how energy is produced, the company cannot be limited to just one market and thus needs to have a presence all around the world. This is 
critically important. Naturally, it is necessary to have partners. However, when advising up-and-coming entrepreneurs who want to make a global impact, the importance of having a real presence with your own employees in the countries in which you have operations should be stressed.

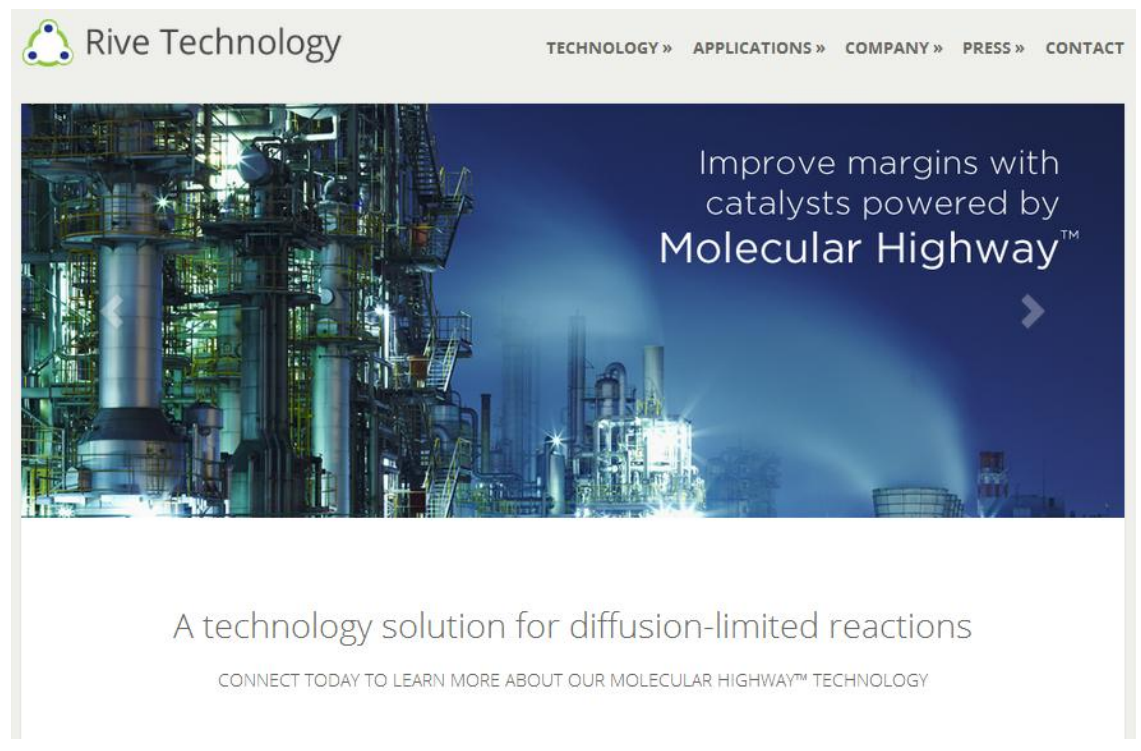

Figure X. Rive's vision.

\section{Concluding Remarks}

There is an important amount of outrageous research being done at universities and research centers around the world, and there are huge market needs that still need to be met. The missing links are the business ideas that allow the research to actually hit the market. Moreover, the products and solutions need to be put in the hands of the public. Once products are on the market and begin to capture value, this value can then be funneled back into research to create more new products and services. But in order to do this, we need more entrepreneurs - people who know the research, know how to solve the problems, are aware of market demands, and who can find ways to commercialize the market, produce the product and create a company around it. The challenges are summarized graphically in Figure 1. 
When considering whether to become an employee or an entrepreneur, think about this quote from Tony Gaskins: "If you don't build your dream, someone will hire you to help build theirs."

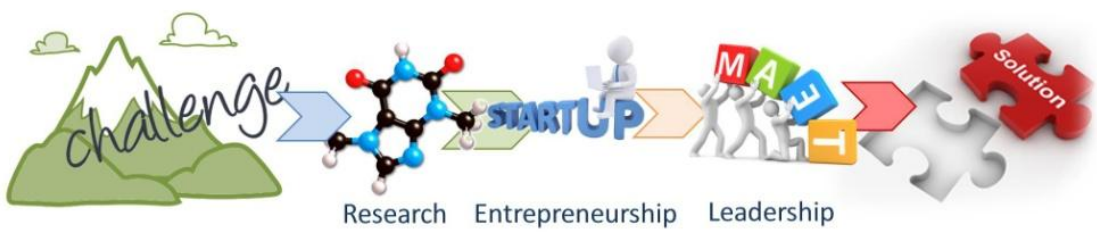

Figure 5. Challenges of starting a new company

\section{References}

1. Garcia-Martinez, J. The Third Way: Becoming an Academic Entrepreneur, Science Careers, March 20, 2014.

2. Li, K.; Valla, J.; Garcia-Martinez, J. Realizing the Commercial Potential of Hierarchical Zeolites: New Opportunities in Catalytic Cracking, ChemCatChem, 2014, 6 (1), 46-66.

3. Li, E.; Garcia Martinez, J. (ed.) Mesoporous Zeolites: Preparation, Characterization and Applications. WILEY-VCH, 2014.

4. Steve Blank: http://steveblank.com/about/ 